\title{
“O QUADRO SENSÍVEL DO POEMA”: O LUGAR DA POESIA NA OBRA DE SOPHIA DE MELLO BREYNER ANDRESEN
}

\section{“THE POEM'S SENSITIVE FRAMEWORK”: THE PLACE OF POETRY IN SOPHIA DE MELLO BREYNER ANDRESEN'S WORK.}

\section{Rogério Camargo*}

FAE

Resumo: Este artigo tem como objetivo investigar o ideário de poesia presente na obra da poeta portuguesa Sophia de Melo Breyner Andresen. Para tanto, serão utilizadas as reflexões presentes nas “Artes poéticas” escritas pela autora, bem como algumas reflexões crítico-teóricas acerca da relação do poeta com a tradição, a exemplo do que propõe T.S. Eliot. No caso de Sophia, o poema aparece como elo entre a noção de totalidade perseguida pela poeta e o próprio real que lhe serve de base para o exercício poético. Muitas vezes, essa relação se vê ameaçada pela dinâmica do tempo e espaço em que a autora vive. Assim, a busca de tal unidade, ao mesmo tempo em que se manifesta na própria escrita do poema, é posta em xeque pelo ato mesmo de escrever.

Palavras-chave: Sophia de Melo Breyner Andresen. Poesia. Realidade.

\begin{abstract}
This article aims to investigate the ideas of poetry present in the work of Portuguese poet Sophia de Melo Breyner Andresen. To this end, we will use the reflections present in the "Poetic arts" written by the author, as well as some critical-theoretical reflections about the relationship of the poet with tradition, as proposed by T.S. Eliot. In Sophia's case, the poem appears as a link between the notion of wholeness pursued by the poet and the real itself that underlies her poetic exercise. This relationship is often threatened by the dynamics of time and space in which the author lives. Thus, the search for such unity, while manifesting itself in the poem's own writing, is challenged by the very act of writing.
\end{abstract}

Keywords: Sophia de Melo Breyner Andresen. Poetry. Reality.

\section{Introdução}

Nascida na cidade do Porto, a poeta portuguesa Sophia de Mello Breyner Andresen (19192004) deu continuidade e vigor a uma poesia cuja marca principal está na indagação metafísica sobre a problemática condição do homem moderno. Mas, ao contrário de muitos autores do seu tempo, que associavam a experiência de choque da modernidade ao prosaísmo, sarcasmo e novidade, Sophia imprimiu em sua poesia, conforme os dizeres de Manuel da Costa Pinto (2004), “um tom mais solene, em que o ofício da escrita equivale à busca do absoluto - sem

*Doutor em Letras. Email: lrcamargo.roger@hotmail.com 
contudo se divorciar do mundo concreto, mas buscando nas coisas elementares um tipo de sacralidade” (PINTO, 2004), ou, como escreveu Eduardo Lourenço (1975), a procura por uma “aliança primitiva”, onde esse mesmo real adquire sentido de verdade.

Dessa postura, advém uma atitude de retorno à essência das coisas, resistindo à parcela das estéticas de total recusa, ruptura e contestação que marcam a modernidade, sem, no entanto, deixar de lado o peso de uma aguda consciência do seu próprio tempo, marcado por um profundo sentimento de divisão que a poeta procura superar.

Como tantos poetas, Sophia também escreveu e falou a respeito de seu próprio fazer poético. Para além dos cinco textos que compõem suas Artes poéticas, publicou, em 1975, um importante ensaio intitulado $O$ nu na Antiguidade Clássica, no qual discorre acerca do mundo grego, sua arte e características, tendo como premissa sobretudo a representação da nudez na estatuária antiga. Escreveu também um breve artigo intitulado “Poesia e realidade”, publicado na Revista de Artes e Letras, em 1960, em que distingue a poesia em si, a relação do homem com a poesia e o conceito de poema. Finalmente, concedeu inúmeras entrevistas ao longo da vida, nas quais fala, entre outras coisas, acerca de sua visão de mundo, seus versos e a relação entre os dois.

Assim sendo, o objetivo deste trabalho é investigar a concepção de poesia na obra de Sophia de Mello Breyner Andresen. A hipótese que norteia estas reflexões parte da premissa de que, para a autora, a poesia é a via de acesso para um ideal de totalidade e inteireza, cuja existência é constantemente ameaçada pelo próprio modo como o homem se relaciona com o real.

\section{“Um princípio incorruptível”}

Na primeira de suas Artes poéticas, publicada, inicialmente, no livro Geografia, de 1967, contando o episódio de uma visita feita a uma loja de produtos artesanais, "uma loja de barros”, na cidade de Lagos, Sophia apresenta uma das metáforas mais significativas a respeito da função do poeta e da poesia de seu tempo. Fazendo um paralelo entre a realidade portuguesa e a realidade grega, estabelece um dos pontos cruciais, uma espécie de síntese, de toda a sua obra: a necessidade de uma religação, do restabelecimento de uma aliança primitiva há muito rompida com o mundo e com o real. Para tanto, dentre as peças encontradas na loja, elege como símbolo dessa aliança uma ânfora. Não, porém, qualquer ânfora, mas uma feita de um barro que, "desde tempos imemoriais os homens aprenderam a modelar numa medida humana” (ANDRESEN, 2015a, p. 889):

Em Lagos em Agosto o sol cai a direito e há sítios onde até o chão é caiado. O sol é pesado e a luz leve. Caminho no passeio rente ao muro mas não caibo na sombra. A sombra é uma fita estreita. Mergulho a mão na sombra como se a mergulhasse na água. A loja dos barros fica numa pequena rua do outro lado da praça. Fica depois da taberna fresca e da oficina escura do ferreiro. Entro na loja dos barros. A mulher que os vende é pequena e velha, vestida de preto. Está em frente de mim rodeada de ânforas (ANDRESEN, 2015a, p. 889).

Interessante notar, de saída, que o caminho até a loja é permeado de um contraste entre luz e sombra, claridade e escuridão, sem que, no entanto, haja predomínio de um sobre outro. 
Assim, o local escolhido para falar da religação “da medida humana” com o sagrado não é completamente luminoso, nem totalmente escuro, mas um lugar onde paira uma "doce penumbra” (ANDRESEN, 2015a, p. 889), como que o resultado de duas forças que se opõem sem que cheguem a subjugar-se completamente. Nesse ambiente, diante das louças espalhadas por todos os cantos, "formas que através dos séculos vêm de mão em mão" (ANDRESEN, 2015a, p. 889), a poeta se sente como que estando na Grécia: “A loja onde estou é como uma loja de Creta” (ANDRESEN, 2015a, p. 889). E, observando as ânforas, reflete a respeito do estatuto da própria arte enquanto poeta, arte esta que exige de si um olhar mais apurado, limpo e ascético. A ânfora, ademais, é também vista como um símbolo de uma beleza, cuja particularidade não pode ser descrita num plano estético, mas somente numa dimensão poética que, ironicamente, vai além das palavras, "tão evidente, tão certa que não pode ser descrita” (ANDRESEN, 2015a, p. 889).

Igual a todas as outras, cujo modelo fora tantas vezes repetido, a ânfora é também sinônimo de uma tradição, que, no entanto, renova-se e mantém-se pelo fato de possuir um "princípio incorruptível” (ANDRESEN, 2015a, p. 890)

Com outras palavras, o poeta e crítico T. S. Eliot também falou dessa permanência da tradição e a relação com o talento individual de cada autor. Para ele, quando uma obra é tomada sem preconceitos do novo em relação ao antigo, pode-se perceber que não apenas o que há de melhor em um poeta, mas igualmente os momentos mais individuais de sua obra são justamente aqueles nos quais os antepassados revelam de modo mais vigoroso a sua imortalidade (ELIOT, 1972, p. 38).

Esse é, para Eliot, o sentido histórico de uma obra ao qual nenhum artista pode fugir. Ao contrário, dado que uma tradição não significa apenas a atribuição de um legado de uma geração a outra, nem a mera repetição mecânica de um modelo, é precisamente esse sentido histórico que permite não apenas a percepção da caducidade do passado, mas a sua presença. Por isso, nenhum poeta tem significação completa sozinho, mas, sim, a partir da relação que estabelece com os que o precederam. Nas palavras do autor, o sentido histórico leva o homem a escrever não apenas com a geração à qual pertence, "mas com um sentimento de que toda a literatura europeia desde Homero e, nela incluída, toda a literatura de seu próprio país têm uma existência simultânea e constituem uma ordem simultânea” (ELIOT, 1972, p. 39).

No caso de Sophia, no interior da loja de ânforas está preservado o símbolo daquilo que não se quebrou. A ânfora representará a aliança primitiva tantas vezes referida como uma necessidade a ser preenchida para a plena concretude do eu. Todavia, embora, por instantes, deixe-se extasiar pela descoberta, a aguda consciência de seu próprio tempo presente não deixa de lembrá-la de que lá fora há um outro mundo, aquele que, de fato, é o seu.

Nesse mundo, a aliança foi quebrada e é dele e em relação a ele que advém um profundo sentimento de exílio e estrangeirismo:

Olho para a ânfora na pequena loja dos barros. Aqui paira uma doce penumbra. Lá fora está o sol. A ânfora estabelece uma aliança entre mim e o sol. Olho para a ânfora igual a todas as outras ânforas, a ânfora inumeravelmente repetida mas que nenhuma repetição pode aviltar porque nela existe um princípio incorruptível. Porém, lá fora na rua, sob o peso do mesmo sol, outras coisas me são oferecidas. Coisas diferentes. Não têm nada de comum nem comigo nem com o sol. Vêm de um mundo onde a aliança foi quebrada. Mundo que não está religado nem ao sol 
nem à lua, nem a Ísis, nem a Deméter, nem aos astros, nem ao eterno. Mundo que pode ser um habitat mas não é um reino. O reino agora é só aquele que cada um por si mesmo encontra e conquista, a aliança que cada um tece (ANDRESEN, 2015a, p. 890).

Conforme afirma, o mundo presente, no qual habita, pode ser um mundo, mas não é um reino. Longe da harmonia e do equilíbrio, o que nele impera é a individualidade egoísta que afasta o eu da plena comunhão com o todo. Por isso a necessidade de uma religação. Assim como o eu que procura, o reino do agora também está dividido e a tarefa do poeta será justamente a de tentar unir esse mundo fragmentado a partir de um projeto e atitude pessoal de envolvimento com o todo. Conforme escreve em "Poesia e Realidade":

A atitude do poeta perante a Realidade é igual à atitude do amante perante um corpo vivo com o qual ele se encontra, vive, se une e se confunde. A poesia só é conhecimento por consequência, isto é, na medida em que de todo o encontro nasce necessariamente conhecimento. O poeta não tem curiosidade do Real, mas sim necessidade do Real. A verdadeira ânsia dos poetas é uma ânsia de fusão e de unificação com as coisas (ANDRESEN, 1960, p. 53)

Todavia, a poeta sabe que não se trata de uma empreitada fácil. Como em um espelho que se partisse em mil pedaços, o eu que observa esse reino dividido se enxerga em cada fragmento, mas não aceita passivamente a divisão e busca reunificá-lo. "Semelhante ao corpo de Orpheu dilacerado pelas fúrias este reino está dividido. Nós procuramos reuni-lo, procuramos a sua unidade, vamos de coisa em coisa” (ANDRESEN, 2015a, p. 890). O esforço dessa busca exige que se ocupe com aquilo que é detalhe, na esperança de uma totalidade, tal qual enuncia no poema homônimo à terceira de suas obras, Coral, publicada em 1950:

\section{CORAL}

Ia e vinha

E a cada coisa perguntava

Que nome tinha (ANDRESEN, 2013 p. 59 CORAL).

Do sentimento de ruptura, volta-se, imediatamente, para o de esperança em um reencontro que, cada vez mais, vai se firmando como propósito premente: "Este é o reino que buscamos nas praias de mar verde, no azul suspenso da noite, na pureza da cal, na pequena pedra polida, no perfume do orégão” (ANDRESEN, 2015a, p. 890). Do fragmento, vê-se que a busca se orienta em dois eixos principais, inicialmente opostos, mas que procuram se harmonizar: o do amplo abstrato e o do ínfimo concreto, abarcando, no percurso, desde a imensidão das praias, do mar e do céu, até a concretude de uma pedra ou o transitório perfume de uma planta.

Ainda na “Arte poética I”, esse mesmo mar será o pano de fundo para a aliança provisoriamente restabelecida. Uma vez encontrado o símbolo da inteireza que vem de um tempo anterior à cisão, a atitude é a de deslocá-lo, transportando-o para esse mundo outro, irremediavelmente dividido. Para tanto, a ânfora é então comprada e posta de frente para o mar. Aliás, na poesia de Sophia, o mar cumpre inúmeras funções e uma das mais importantes é a de símbolo do 
incomensurável, bem como uma via, um caminho de regresso para outro tempo, já conhecido, mas que se delineia no processo da jornada:

Navegavam sem o mapa que faziam

(Atrás deixando conluios e conversas

Intrigas surdas de bordéis e paços)

Os homens sábios tinham concluído

Que só podia haver o já sabido:

Para frente era só o inavegável

Sob o clamor de um sol inabitável [...] (ANDRESEN, 2015b, p. 40).

Esse mar, ora desconhecido, ora via de acesso a certa plenitude, será também inúmeras vezes cantado como um lugar de repouso e felicidade, diante do qual existirão como memória a casa antiga e o jardim da infância. "É por isso que eu levo a ânfora de barro pálido e ela é para mim preciosa. Ponho-a sobre o muro em frente do mar. Ela é ali a nova imagem da minha aliança com as coisas” (ANDRESEN, 2015a, p. 890).

\section{A “aliança ameaçada”}

Como já dito, trata-se de uma aliança provisória, porque sequer o sentimento de religação pode ser fruído com tranquilidade. Ao contrário, quanto mais se aproxima de uma possível retomada da unidade, mais evidente é o sentimento de ameaça e proscrição em face ao mundo que a rodeia. "Aliança ameaçada. Reino que com paixão encontro, reúno, edifico. Reino vulnerável. Companheiro mortal da eternidade” (ANDRESEN, 2015a, p. 890, minha ênfase). A unidade, como se percebe, está ali, ao alcance da mão. No entanto, sua segurança não é garantida fora do ambiente ideal. No mundo da poeta, nada pode assegurar sua integridade, a não ser a palavra poética que, além de um modo de entendimento do real e do universo é, para Sophia, uma maneira de resistência a seu próprio tempo e lugar:

\section{POEMA}

Cantaremos o desencontro:

O limiar e o linear perdidos

Cantaremos o desencontro:

A vida errada num país errado

Novos ratos mostram a avidez antiga (ANDRESEN, 2015c, p. 102).

Em 1978, ao ser questionada pelo poeta e crítico Walmir Ayala a respeito do significado da poesia em sua vida, Sophia explicou: “A poesia é a minha explicação com o universo, a minha relação com as coisas, a busca duma totalidade, a criação quotidiana da liberdade" (ANDRESEN, 1978, p. 78, grifo nosso). Para ser livre e total, na visão da poeta, é preciso criar, e esse processo está relacionado a uma espécie de arte do ser e não de uma simples técnica. 
No texto “Arte poética II”, também publicado inicialmente em Geografia, é precisamente esse o ponto de partida de suas considerações:

A poesia não me pede propriamente uma especialização pois a sua arte é uma arte do ser. Também não é tempo ou trabalho o que a poesia me pede. Nem me pede uma ciência nem uma estética nem uma teoria. Pede-me antes a inteireza do meu ser, uma consciência mais funda do que a minha inteligência, uma fidelidade mais pura do que aquela que eu posso controlar. Pede-me uma intransigência sem lacuna. Pede-me que arranque da minha vida que se quebra, gasta, corrompe e dilui uma túnica sem costura. Pede-me que viva atenta como uma antena, pede-me que viva sempre, que nunca me esqueça. Pede-me uma obstinação sem tréguas, densa e compacta (ANDRESEN, 2015a, p. 891, ênfase minha).

Negando a kritike tekhne ${ }^{1}$ dos gregos, a poesia não é vista pela poeta apenas como uma especialização. À moda de Heidegger - “A linguagem é a casa do ser. É nessa morada que habita o homem” (HEIDEGGER, 2005, p. 8) - Sophia entende que a poesia, porque feita de linguagem, é uma arte do ser e não apenas da técnica.

Na visão da poeta, entretanto, sendo o homem admitidamente falho e corruptível, a poesia, ao exigir o que não se quebra, o que não se desgasta, termina por pedir mais do que esse mesmo homem pode oferecer. Em outras palavras, pede do humano uma medida demasiadamente alta para essa humanidade. Ao impor da poeta que se livre de toda a possibilidade de corrupção, a poesia demanda não menos do que a atenção total para com um mundo, na essência, conspurcado.

Diante de tais exigências, o eu-poético se vê mergulhado num tormentoso paradoxo. E a solução para tal impasse não deixa de seguir via menos contraditória. Sendo a poesia seu modo de explicação com o universo, como afirma, será o poema, ao mesmo tempo, um modo de convivência com as coisas que compõem esse mesmo universo em sua totalidade, incluindo "a participação no real, o meu encontro com as vozes e as imagens” (ANDRESEN, 2015a, p. 891).

Como é possível perceber, as imagens que remontam a uma totalidade são uma verdadeira obsessão na poética de Sophia. O grande problema, no entanto, está no fato de a poeta buscá-la em um mundo que, em tudo, representa o contrário do desejado:

o poema não fala de uma vida ideal mas sim de uma vida concreta: ângulo da janela, ressonância das ruas, das cidades e dos quartos, sombra dos muros, aparição dos rostos, silêncio, distância e brilho das estrelas, respiração da noite, perfume da tília e do orégão (ANDRESEN, 2015a, p. 891, ênfase minha).

Se, para Sophia, a poesia exige uma atenção total em relação ao real, pede-lhe que viva “atenta como uma antena”, de maneira que, ao poeta, é impossível furtar-se à vida concreta, conforme escreve na "Arte poética III'”:

O artista não é, e nunca foi, um homem isolado que vive no alto duma torre de marfim. O artista, mesmo aquele que mais se coloca à margem da convivência,

\footnotetext{
${ }^{1}$ Traduzida, posteriormente, em latim por ars critica, a expressão era tomada na acepção antiga com o significado de "habilidade”, "técnica”, "perícia".

${ }^{2} \mathrm{O}$ texto é proveniente de um discurso proferido por Sophia, em 11 de Julho de 1964, no almoço organizado pela Sociedade Portuguesa de Escritores por ocasião da entrega do Grande Prêmio de Poesia atribuído a Livro Sexto (1962). Posteriormente foi incorporado como posfácio do mesmo livro.
} 
influenciará necessariamente, através da sua obra, a vida e o destino dos outros. Mesmo que o artista escolha o isolamento como melhor condição de trabalho e criação, pelo simples facto de fazer uma obra de rigor, de verdade e de consciência ele irá contribuir para a formação duma consciência comum. Mesmo que fale somente de pedras ou de brisas a obra do artista vem sempre dizer-nos isto: Que não somos apenas animais acossados na luta pela sobrevivência mas que somos, por direito natural, herdeiros da liberdade e da dignidade do ser (ANDRESEN, 2015a, p. 894, ênfase minha).

Para Sophia, o fundamento do poema está na relação que este permite estabelecer com o universo, uma vez que "quando há apenas relação com uma matéria há apenas artesanato" (ANDRESEN, 2015a, p. 891).

A ânfora é, em princípio, artesanal. Contudo, paradoxalmente, para fazer parte do real, precisa transcender o real. Evidentemente, todo artesanato exige algum tipo de especialização, uma certa ciência, um trabalho, um tempo e uma estética. Todo poeta, nesse sentido, é também um artesão da palavra, um artífice da linguagem. Especificamente no caso da arte poética, o artesanato não nasce de si mesmo, mas da relação com uma matéria específica: a vida.

Se um poeta diz «obscuro», «amplo», «barco», «pedra» é porque estas palavras nomeiam a sua visão do mundo, a sua ligação com as coisas. Não foram palavras escolhidas esteticamente pela sua beleza, foram escolhidas pela sua realidade, pela sua necessidade, pelo seu poder poético de estabelecer uma aliança. E é da obstinação sem tréguas que a poesia exige que nasce o «obstinado rigor» do poema. O verso é denso, tenso como um arco, exactamente dito, porque os dias foram densos, tensos como arcos, exactamente vividos. $\mathrm{O}$ equilíbrio das palavras entre si é o equilíbrio dos momentos entre si. E no quadro sensível do poema vejo para onde vou, reconheço o meu caminho, o meu reino, a minha vida. (ANDRESEN, 2015a, p. 892, ênfase minha).

Nesse “quadro sensível do poema” é que a poeta procurará reconhecer o seu lugar.

\section{“A unidade da nossa consciência”}

Assim como a loja de barros, inúmeros outros lugares representam, na obra de Sophia, um lugar de inteireza. Dado que esse universo poético está constantemente sob ameaça, sob uma tensão que se torna mais evidente a cada poema, esses mesmos lugares, não raro, apresentam significados diferentes. Por vezes, até em um mesmo poema ou verso. No texto denominado na terceira de suas “Artes poéticas”, a casa aparece como um desses lugares onde Sophia igualmente procurará o restabelecimento de um reino e sua inteireza.

A esse lugar a poeta voltará através do exercício da memória: “A coisa mais antiga de que me lembro é dum quarto em frente do mar dentro do qual estava, poisada em cima duma mesa, uma maçã enorme e vermelha. Do brilho do mar e do vermelho da maçã erguia-se uma felicidade irrecusável, nua e inteira” (ANDRESEN, 2015a, p. 893). Essa felicidade, mais tarde, será confirmada por meio de uma leitura da tradição que a conduzirá pelas sendas sem volta do caminho grego. "Em Homero reconheci essa felicidade nua e inteira, esse esplendor da presença das coisas” (ANDRESEN, 2015a, p. 893). 
A Maria da Conceição Casais, Sophia conta, em entrevista, a respeito do primeiro contato com a cultura e a mitologia gregas. Foi no mesmo ano em que aprendera a ler. Na época, Sophia recorda de ter passado alguns dias em umas termas com a sua mãe. Por não ter nada para ler, pediu que fossem em busca de algum lugar em que se vendessem livros:

Fomos a uma espécie de tabacaria, que era o único sítio onde aí se vendiam livros e escolhi um que se chamava Mitologia Grega porque me fascinei com as fotografias de diversas estátuas. Lembravam-me o mar, qualquer coisa da claridade, da respiração do mar e do ritmo das ondas. Mais tarde, quando tinha doze anos, encontrei uma tradução da Odisseia do Leconte de Lisle e lembro-me que esse livro tornou-me presente o Verão, o mar, a relação com o mundo que eu queria (ANDRESEN, 1989, p. 55, ênfase minha).

A descoberta desse mundo grego foi uma verdadeira revelação à pequena Sophia. E está de tal modo enraizado em seus escritos, que neles encontra rival apenas na onipresença da tradição cristã. Reafirmando o papel da poesia como uma constante perseguição do real, Sophia explica: "um poema foi sempre um círculo traçado à roda duma coisa, um círculo onde o pássaro do real fica preso” (ANDRESEN, 2015a, p. 893, ênfase minha), fruto da já referida busca atenta.

Para a poeta, a procura de uma relação justa com o real a conduzirá a uma relação justa com a natureza e com o homem. "Aquele que vê o espantoso esplendor do mundo é logicamente levado a ver o espantoso sofrimento do mundo. Aquele que vê o fenómeno quer ver todo o fenómeno. É apenas uma questão de atenção, de sequência e de rigor” (ANDRESEN, 2015a, p. 893, ênfase minha).

Assim, longe de buscar na sabedoria dos antigos como um simples paliativo para a sua angústia, um modo de evitar o sofrimento a qualquer custo, a proposta de Sophia é jamais se furtar a esse sofrimento. Sua postura, nesse sentido, é a de um altivo enfrentamento desse doloroso espetáculo, ainda que o preço a pagar seja o dilaceramento do próprio eu.

Por isso, sua poesia, tomada como uma moral, será também uma constante busca por justiça em um mundo essencialmente injusto. E é nesse aspecto que se encontra um dos pontos mais altos acerca do tema em toda a sua obra, verdadeiro manifesto da crença no papel social da arte como agente transformador do mundo do qual faz parte, conforme escreve ainda na “Arte poética III”:

E é por isso que a poesia é uma moral. E é por isso que o poeta é levado a buscar a justiça pela própria natureza da sua poesia. E a busca da justiça é desde sempre uma coordenada fundamental de toda a obra poética. Vemos que no teatro grego o tema da justiça é a própria respiração das palavras. Diz o coro de Ésquilo: «Nenhuma muralha defenderá aquele que, embriagado com a sua riqueza, derruba o altar sagrado da justiça.» Pois a justiça se confunde com aquele equilíbrio das coisas, com aquela ordem do mundo onde o poeta quer integrar o seu canto. Confunde-se com aquele amor que, segundo Dante, move o Sol e os outros astros. Confunde-se com a nossa confiança na evolução do homem, confunde-se com a nossa fé no universo. Se em frente do esplendor do mundo nos alegramos com paixão, também em frente do sofrimento do mundo nos revoltamos com paixão. Esta lógica é íntima, interior, consequente consigo própria, necessária, fiel a si 
mesma. O facto de sermos feitos de louvor e protesto testemunha a unidade da nossa consciência (ANDRESEN, 2015a, p. 894, ênfase minha).

O mundo injusto de que fala a poeta é o seu mundo presente. A sua busca de um "estar-ser-inteiro inicial das coisas” (ANDRESEN, 2014, p. 77) exige um rito de regresso a um passado que ofereça bases sólidas para que, a partir de um presente despedaçado, possa projetar-se em direção a um futuro no qual poderá reaver o que se perdeu. A Grécia antiga representa esse tempo e o sagrado que a anima é o objetivo desse regresso. Para tanto, é necessária uma harmonização com a natureza e com as coisas que a visão grega formula e estabelece, conforme explica em entrevista concedida a Maria Armanda Passos:

A Grécia é um ponto de partida a que justamente é preciso regressar porque então o homem tentou partir da imanência, partir do seu estar na terra: estou na terra, sou mortal mas vou tentar viver a minha mortalidade com o máximo de verdade, o máximo de transparência, o máximo de... (ANDRESEN, 1982, p. 4).

Todavia, a Grécia de Sophia não é qualquer Grécia, mas aquela na qual os mitos e seus deuses ainda se fazem sentir, cujas presenças podem ser percebidas desde que se tenha a devida atenção. Ao mesmo tempo, diante de qualquer possibilidade de plenitude, existe sempre uma ameaça de destruição à qual é preciso se opor.

Em busca do equilíbrio que percebe na arte grega, Sophia entenderá a poesia como uma forma de enfrentar a voragem, conforme explica em outra entrevista, desta vez concedida a Miguel Serras Pereira, em 1985: "Sem dúvida, a palavra é uma forma de não se ser devorado pelo caos, pela confusão, pela contradição e o tumulto, apesar de ter um pacto com tudo isso e de sem isso não atingir a sua plenitude” (ANDRESEN, 1985, p. 3).

Ainda assim, o mesmo poema que serve como via de combate é também parte da própria tensão que procura combater. É o que consta em sua “Arte poética IV”, publicada pela primeira vez em Dual (1972), talvez um de seus livros mais gregos: "Sei que o poema aparece, emerge e é escutado num equilíbrio especial da atenção, numa tensão especial da concentração" (ANDRESEN, 2015a, p. 895, ênfase minha).

Os deuses e ritos gregos representam a busca dessa inteireza, mas que, assim como o eu e o poema, também podem se quebrar a qualquer instante. Não se trata, portanto, de uma poética maniqueísta, na qual os opostos se repelem num jogo de tudo ou nada, mas, antes, de uma relação entre pares que, embora quase sempre se contradigam, fundam-se a partir de tensões e paradoxos, numa verdadeira dialética entre Caos e Cosmos:

Não temo a transparência mas sim a sua contínua destruição. Mallarmé disse que o poeta vem transformar o caos em cosmos. Há um desorganizado, um balbuciante, uma confusão latente que nunca são completamente clarificados e ninguém consegue criar uma transparência total. Delfos é “o lugar trágico" em que Apolo, deus da claridade, da transparência, da geometria e da música enfrenta o dragão, a serpente Python. E a palavra "pythô» significa «apodreço». Apolo não enterra a serpente, ela fica a apodrecer (ANDRESEN, 1982, p. 4, ênfase minha). 
Para Sophia, o poema, em si, não é o caos, mas é proveniente de um caos que jamais se resolve completamente e que está na origem de todas as coisas. "O poema é arrancado ao caos e traz ainda a sua ressonância, os seus ecos.” (ANDRESEN, 1982, p. 4). Esse caos primevo não deve ser confundido com o mal, que se configura em uma negatividade plena "um puro princípio de destruição” do qual nada advém, senão o próprio mal (ANDRESEN, 1982, p. 4). O caos, conforme visto por Sophia, está relacionado a um mundo de coisas múltiplas, divergentes, contraditórias, muitas vezes assustadoras que ninguém pode organizar de todo dentro de si, tampouco decifrar e compreender de modo satisfatório. Ao mesmo tempo, não deixa de ser uma fonte de riqueza que tem como principal característica ser, desde o princípio dos tempos, uma força de recriação. "Em Hesíodo ao princípio era o caos. E na Bíblia 'as trevas que cobriam a face do abismo’ são ainda o caos, do qual Deus vai tirar o mundo ordenado, dividindo as águas, dividindo a noite do dia....” (ANDRESEN, 1982, p. 4).

O caos é o princípio de todas as coisas. Uma vez que o objetivo da poeta é o retorno a esse princípio, evidentemente, sua poética não pode ignorar a fonte da qual tudo provém. De modo análogo, se o poema é tomado no sentido de um caos, o trabalho do poeta será o de transformar esse caos em cosmo, a busca do que chamou, em sua "Arte poética V" o "poema imanente” (ANDRESEN, 2015a, p. 898).

\section{Mais Algumas Considerações}

Conforme visto, um dos motivos mais insistentes na poética de Sophia de Melo Breyner Andresen diz respeito à relação do poeta com a realidade que o circunda. Devido à aguda consciência das fragilidades de seu próprio tempo e espaço, o poema surge como ponto intermediário entre o sujeito poético e um ideal sempre por alcançar. Tal ideal consiste na noção de uma inteireza que, embora quebrada, permanece intuída e que, por isso mesmo, move a poeta em busca de seu restabelecimento.

Tarefa árdua, só é possível graças ao olhar atento para essa mesma realidade. Nela, junto ao caos imanente, subjaz a possibilidade da ordenação criadora, de maneira que a postura do poeta diante do real é a de quem resiste à sucessão de rupturas, mediante "uma ânsia de fusão e de unificação com as coisas” (ANDRESEN, 1960, p. 54). Isso porque, a toda 'aliança ameaçada' corresponde um 'princípio incorruptível”, e vice-versa, de maneira que “o poema é o selo da aliança do homem com as coisas” (ANDRESEN, 1960, p. 54).

\section{Referências}

ANDRESEN, Sophia de Mello Breyner. Poesia e realidade. In: Colóquio - Revista de Artes e Letras. Lisboa: Fundação Calouste Gulbenkian, n. 8, Abril de 1960, p. 53-54.

Artes poéticas. In:

. Obra poética. Colecção dirigida por Carlos Mendes de Sousa. Lisboa: Assírio \& Alvim, 2015a.

Coral. Colecção dirigida por Carlos Mendes de Sousa. Lisboa: Assírio \& Alvim, 2013.

. Dual. Colecção dirigida por Carlos Mendes de Sousa. Lisboa: Assírio \& Alvim, 2014. 
- Navegações. Colecção dirigida por Carlos Mendes de Sousa. Lisboa: Assírio \& Alvim, 2015b.

. O nome das coisas. Colecção dirigida por Carlos Mendes de Sousa. Lisboa:

Assírio \& Alvim, 2015c.

Janeiro, 1978.

“Poesia é criação cotidiana da liberdade”. Entrevista de Walmir Ayala. Rio de . “Sophia: «E o brilho do visível frente a frente»”. Entrevista de Maria da Conceição Casais. In: Contemporânea, 15 de março de 1989.

- Sophia de Mello Breyner Andresen: "Escrevemos poesia para não nos afogarmos no cais”. Entrevista a Maria Armanda Passos. In: Jornal de Letras, 16 de fevereiro de 1982.

. “Sophia: Sou uma mistura de Norte e Sul”. Entrevista de Miguel Serras Pereira. In: Jornal de letras, 5 de fevereiro de 1985.

ELIOT. T.S. A essência da poesia. Tradução de Maria Luiza Nogueira. Rio de Janeiro: Artenova, 1972.

HEIDEGGER, Martin. Carta sobre o humanismo. 2 ed. rev. Tradução de Rubens Eduardo Frias. São Paulo: Centauro - 2005

LOURENÇO, Eduardo. Prefácio. In: ANDRESEN, Sophia de Mello Breyner. Antologia. Lisboa: Moraes Editores, 1975. p. I-VII.

PINTO, Manuel da Costa. Sophia de Mello Breyner deu vigor à poesia sobre o homem moderno. Folha de São Paulo - Ilustrada, 2004. Disponível em: http://www1.folha.uol.com. br/folha/ilustrada/ult90u45631.shtml Acesso em: 17 out. 2013.

Recebido em setembro/2019.

Aceito em outubro/2019. 